\title{
Calculation and Characterization of the EEJ Current Density from Ground-Based Magnetometer Data Using Ampere's Law
}

\author{
Lamessa Abebe ${ }^{1}$, Gebeyehu Dirbeba ${ }^{2}$ \\ ${ }^{1,2}$ Department of Physics, Mettu University, Ethiopia,
}

\begin{abstract}
In this study, we characterized an empirical model of the equatorial electrojet (EEJ) current density from ground-based magnetometer data using Ampere's law. An analysis was carried out using the equatorial electrojet current, calculated from the geomagnetic northward $\Delta H$ component. The result showed that the EEJ component derived from the model exhibits a similar pattern with measured EEJ from ground data during noontime, mainly before 1300 LT. For different months, the EEJ current density follows the same basic pattern. The EEJ is mostly observed close to local noon, when the E-region conductivity peaks. For this reason, only data from 6:00-18:00 LT are included in this study. The EEJ current density rises sharply to a maximum between 10:30-13:00 LT, and gradually decreases and finally vanishes at around 18:00 LT. The morphology of the amplitude curves obtained for current density diurnal variation with a peak at 10:30-13:00 LT might be interpreted to be due to the signature of EEJ-field.

Key Terms: equatorial electrojet (EEJ), EEJ current density, EEJ-field, Magnetometer Data, Ampere's Law
\end{abstract}

\section{Introduction}

Current density is a measure of the density of electrical current. It is defined as a vector whose magnitude is the electric current per unit length. In SI unit, the current density is measured in amperes per meter. Electrical current is a coarse, average quantity that tells what is happening in an entire wire. If we want to describe the distribution of the charge flow, we use the concept of the current density. In the magnetostatic approximation, the magnetic field can be determined if the current density $\mathbf{J}$ is known. The main work of this project is to determine the current density of the noontime equatorial electrojet (EEJ) by inverting the EEJ-field data obtained from ground-based magnetometer at AAE and ADIE in Ethiopia to investigate the characteristics of this current density.

\section{Equatorial Electrojet Conductivity}

The cause of the Equatorial Electrojet lies a spacial equatorial phenomena of the electrical conductivity of the upper atmosphere. The ionosphere may be considered as an infinite, lightly ionized gas in which there are $\mathrm{n}_{\mathrm{r}}$ charged particles of the $\mathrm{r}^{\text {th }}$ type per cubic centimeter, where $\mathrm{r}=\mathrm{e}$, plus or minus for electrons, positive and negative ions respectively. Let a particle of the $r^{\text {th }}$ type have charge $e_{r}$, mass $m_{r}$, collision frequency with neutral particles $v_{\mathrm{r}}$, and gyro-frequency $\omega=\frac{\mathrm{e}_{\mathrm{r}} \mathrm{B}}{\mathrm{m}_{\mathrm{r}}}$, where B is the intensity of the magnetic field. In the ionosphere, neutral particles are generally much greater in number than charged particles. Consequently, collisions with neutral particles have a large influence on the conductivity values. Let $v_{e}, v_{+}$and $v_{-}$denote the effective collision frequencies of electrons, positive ions, and negative ions, respectively, with all particle types. Similarly, the effective masses are denoted by $\mathrm{m}_{\mathrm{e}}, \mathrm{m}_{+}$and $\mathrm{m}_{-}$, and the corresponding cyclotron frequencies by $\omega_{e}, \omega_{+}$and $\omega_{-}$. We consider the general case in which an applied electric field is neither parallel nor perpendicular to geomagnetic field. The current density $\mathrm{J}$ can be related to the electric field through the following general formula.

$$
\mathrm{J}=\sigma \cdot \mathrm{E}
$$

where $\sigma$ is the electric conductivity. The conductivity of the ionosphere can be classified as, parallel conductivity, $\sigma_{0}$, Pedersen (transverse) conductivity, which is denoted by $\sigma_{1}$ or $\sigma_{\mathrm{p}}$. Hall conductivity, designated by $\sigma_{2}$ or $\sigma_{\mathrm{H}}$, the Cowling conductivity, which is represented by $\sigma_{\mathrm{c}}$.

The parallel component is aligned with the direction of the Earth's magnetic field, the Pedersen conductivity is aligned with the electric field, and the Hall conductivity is perpendicular to both the magnetic and electric fields. As a result, ions and electrons respond differently to the electric field, E, in the presence of the magnetic field, B. Because of this, ions move essentially in the direction of, E, and are mainly responsible for the Pederson conductivity, whereas electrons move mainly at right angles to E and B and give rise to Hall conductivity. Then an electric polarization charges develop in areas where the electric Hall current cannot close. This polarization electric field generates secondary Hall currents in the direction of the Pedersen currents. It is now clear that the resulting increased ionospheric conductivity is a cause to account for all the observed quiet day geomagnetic variations. Consider the ionosphere as a plane sheet. Take the $\mathrm{x}$ and $\mathrm{y}$-axes in this plane to coincide with 
magnetic south and east, respectively, whereas the z-axis points downward. Let the magnetic field, B dip at an angle I to the plane. Let $\mathrm{i}, \mathbf{j}, \mathbf{k}$ be unit vectors in the directions of $\mathrm{x}, \mathrm{y}$, and $\mathrm{z}$, respectively. Figure 1 is the usual Cartesian coordinate system that we use to demonstrate the components of the Earth's magnetic field.

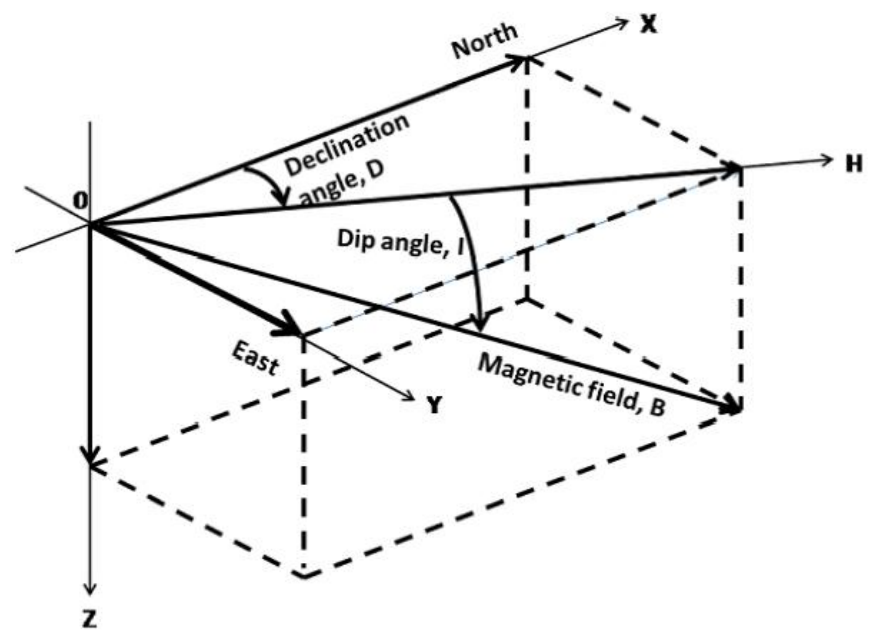

Figure 1: The usual Cartesian coordinate system. Here, $x$ points toward the magnetic north, $y$ toward east and $z$ toward the Earth's center. The H-component represents the horizontal component of the magnetic field.

The electric and magnetic field on this coordinate system are given by

$$
E=E_{x} i+E_{y} j+E_{z} k
$$

And

$$
\mathrm{B}=\mathrm{B}(\cos \mathbf{I} \mathbf{i}+\sin \mathbf{I} \mathbf{k})=\mathrm{Bb}_{0}, \quad \mathrm{~b}_{0}=\cos \mathbf{I} \cdot \mathbf{i}+\sin \mathbf{I} \cdot \mathbf{k}
$$

The current density given by equation (1) has components in all these directions and can be given by,

$$
\mathbf{j}=\sigma_{0}\left(\mathbf{E}_{\mathbf{0}} \cdot \mathbf{b}_{\mathbf{0}}\right) \mathbf{b}_{\mathbf{0}}+\sigma_{1} \mathbf{E}_{\mathbf{1}}-\sigma_{2}\left(\mathbf{E} \times \mathbf{b}_{\mathbf{0}}\right),
$$

All the components of the current density in terms of simplified tensor is as follows:

At the dip equator, where $\mathrm{I}=0$, equation (5) reduces to

$$
\left(\begin{array}{l}
j_{\mathrm{x}} \\
\mathrm{j}_{\mathrm{y}} \\
\mathrm{j}_{\mathrm{z}}
\end{array}\right)=\left(\begin{array}{ccc}
\sigma_{\mathrm{p}} \sin ^{2} \mathrm{I}+\sigma_{0} \cos ^{2} \mathrm{I} & -\sigma_{\mathrm{H}} \sin I & \left(\sigma_{0}-\sigma_{\mathrm{p}}\right) \sin I \cos I \\
\sigma_{\mathrm{H}} \operatorname{sinI} & \sigma_{\mathrm{p}} & -\sigma_{\mathrm{H}} \cos I \\
\left(\sigma_{0}-\sigma_{\mathrm{p}}\right) \sin I \cos I & \sigma_{\mathrm{H}} \cos \mathrm{I} & \sigma p \cos ^{2} \mathrm{I}+\sigma_{0} \sin ^{2} \mathrm{I}
\end{array}\right)\left(\begin{array}{c}
\mathrm{E}_{\mathrm{x}} \\
\mathrm{E}_{\mathrm{y}} \\
\mathrm{E}_{\mathrm{z}}
\end{array}\right)
$$

$$
\left(\begin{array}{l}
\mathrm{j}_{\mathrm{x}} \\
\mathrm{j}_{\mathrm{y}} \\
\mathrm{j}_{\mathrm{z}}
\end{array}\right)=\left(\begin{array}{ccc}
\sigma_{0} & 0 & 0 \\
0 & \sigma_{\mathrm{p}} & -\sigma_{\mathrm{H}} \\
0 & \sigma_{\mathrm{H}} & \sigma_{\mathrm{p}}
\end{array}\right)\left(\begin{array}{l}
\mathrm{E}_{\mathrm{x}} \\
\mathrm{E}_{\mathrm{y}} \\
\mathrm{E}_{\mathrm{z}}
\end{array}\right)
$$

Since the vertical current is inhibited (i.e. $\mathrm{jz}=0$ ) at the equatorial E-region, due to low conductivities above and below E-region, then from equation (6) we get

and the corresponding west-east current, jy, becomes

$$
\mathrm{E}_{\mathrm{z}}=\frac{\sigma_{\mathrm{H}}}{\sigma_{\mathrm{p}}} \mathrm{E}_{\mathrm{y}}
$$

$$
\mathrm{j}_{\mathrm{y}}=\left(\sigma_{\mathrm{p}}+\frac{\sigma_{\mathrm{H}}^{2}}{\sigma_{\mathrm{p}}}\right) \mathrm{E}_{\mathrm{y}}=\sigma_{\mathrm{C}} \mathrm{E}_{\mathrm{y}}
$$

Where $\sigma_{\mathrm{C}}$ is

$$
\sigma_{\mathrm{C}}=\left(\sigma_{\mathrm{p}}+\frac{\sigma_{\mathrm{H}}^{2}}{\sigma_{\mathrm{p}}}\right)
$$

called the Cowling conductivity. Hence, equation (8) represents the EEJ current.

Therefore, The equatorial electrojet is so strong because the vertical currents are strongly inhibited at the magnetic equator, since no vertical currents flows parallel to (and $\sigma_{0} \gg \sigma_{\mathrm{H}}, \sigma_{\mathrm{p}}$ ) the magnetic field. Below $90 \mathrm{~km}$ the conductivity decrease rapidly because of the increasing collision frequencies and above $140 \mathrm{~km}$ ions become magnetized and so the electrons and ions $\mathrm{E} \times \mathrm{B}$ drift together and the Hall conductivity drops. As a 
crude approximation, we consider the electrojet layer, centered at about $103-105 \mathrm{~km}$, to be bounded above and below by insulating regions. Polarization charges build up on these boundaries to almost prevent vertical current flow in the layer.

\section{Calculation and Characterization of EEJ Current Density from Magnetometer Data}

The EEJ is considered as a current strip, flowing eastward along the geomagnetic equator, at an altitude $\mathrm{h}=105 \mathrm{~km}$. To calculate the current density, let us consider an infinite current sheet described by length each carrying current I, which is infinitesimally thin but infinitely long and wide. The sheet has a linear current density (i.e. current per unit length), J. We wish to find the magnetic field direction and magnitude at point $\mathrm{P}$ a distance $\mathrm{h}$ away from the sheet by using Ampere's law. Ampere's law is the Maxwell equation that relates the magnetostatic field (flux) to the source of the magnetostatic field (current). Consider the schematic representation of an infinite current sheet shown as Figure 2 below carrying a current density $J(A / m)$ flowing in the eastward direction.

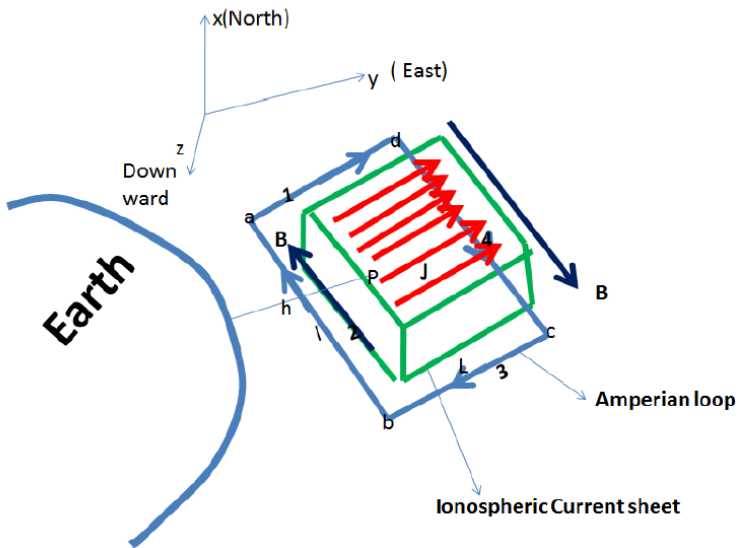

Figure 2: An infinite sheet of current carrying a current density per unit length $J(A / m)$ flowing in the $y$ direction.

\section{Results and Discussions}

The data set consists of hourly values of EEJ-field for a year 2010 at two stations in Ethiopia at AAE and ADIE obtained by subtracting ADIE hourly values from AAE hourly values. In figure 3-5 we plot the local time dependence of the EEJ current density for three months of the year 2010. For different months, the EEJ current density follows the same basic pattern. The EEJ is mostly observed close to local noon, when the Eregion conductivity peaks. For this reason, only data from 6:00-18:00 LT are included in this study. The EEJ current density rises sharply to a maximum between 10:30-13:00 LT, and gradually decreases and finally vanishes at around 18:00 LT. The morphology of the amplitude curves obtained for current density diurnal variation with a peak at 10:30-13:00 LT might be interpreted to be due to the signature of EEJ-field.

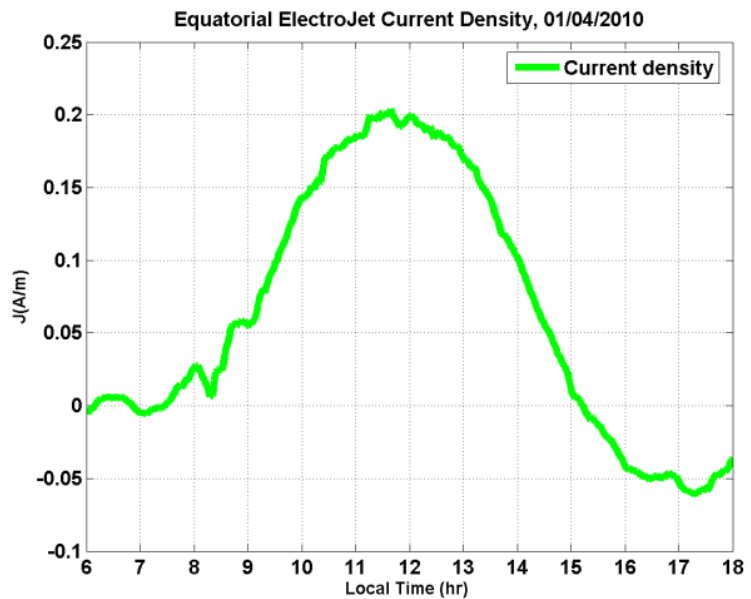



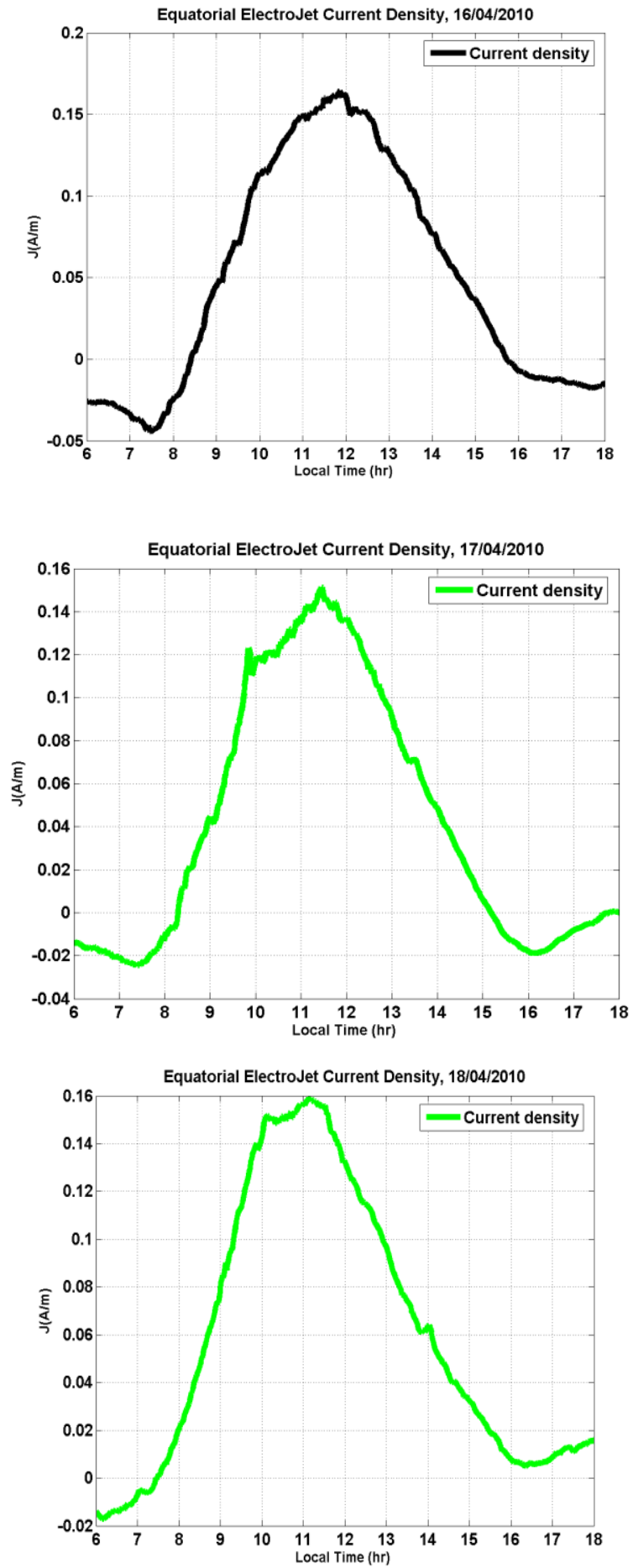

Figure 3: Local time dependence of EEJ current density for April, 2010. 

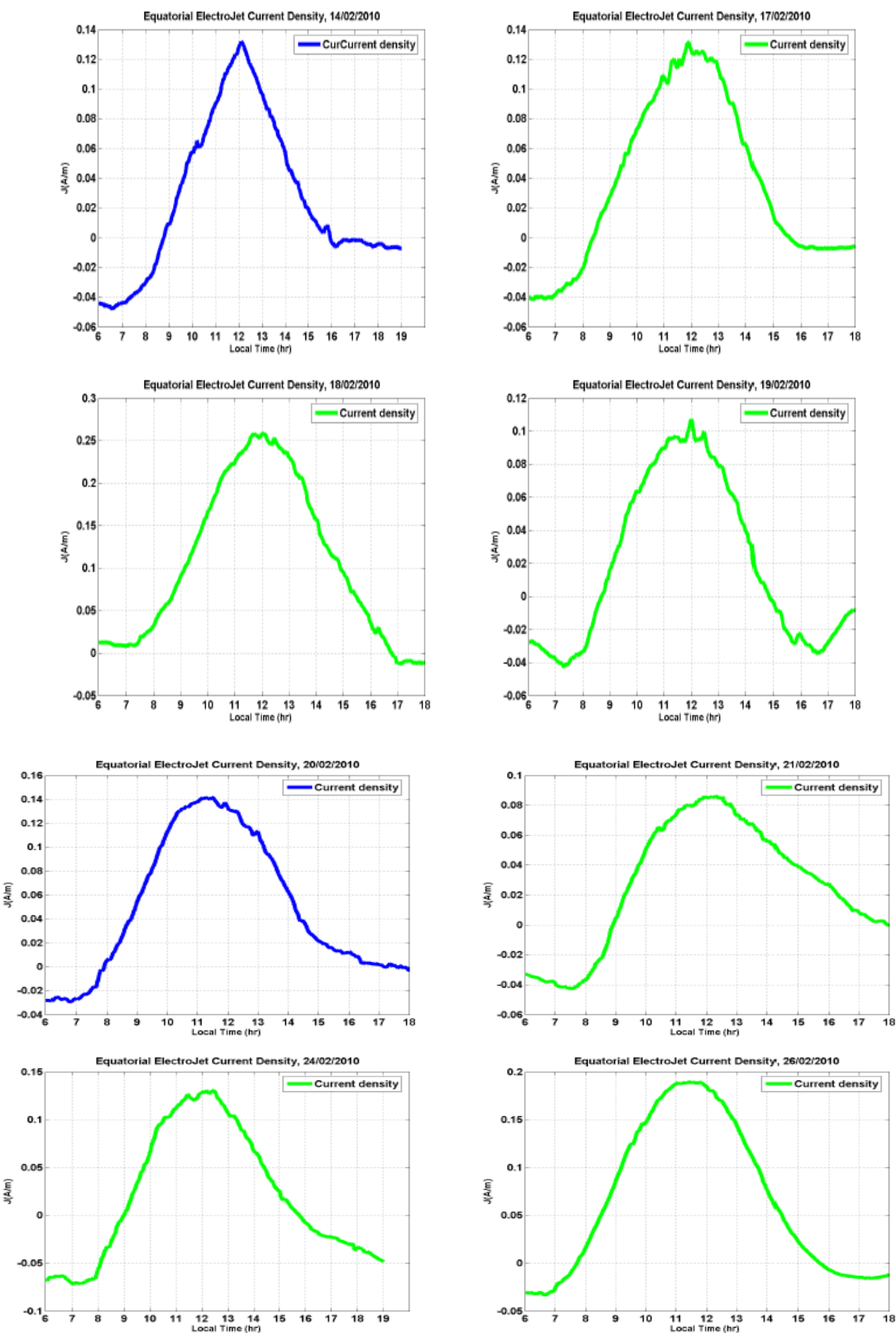

Figure 4: Local time dependence of EEJ current density for February, 2010. 

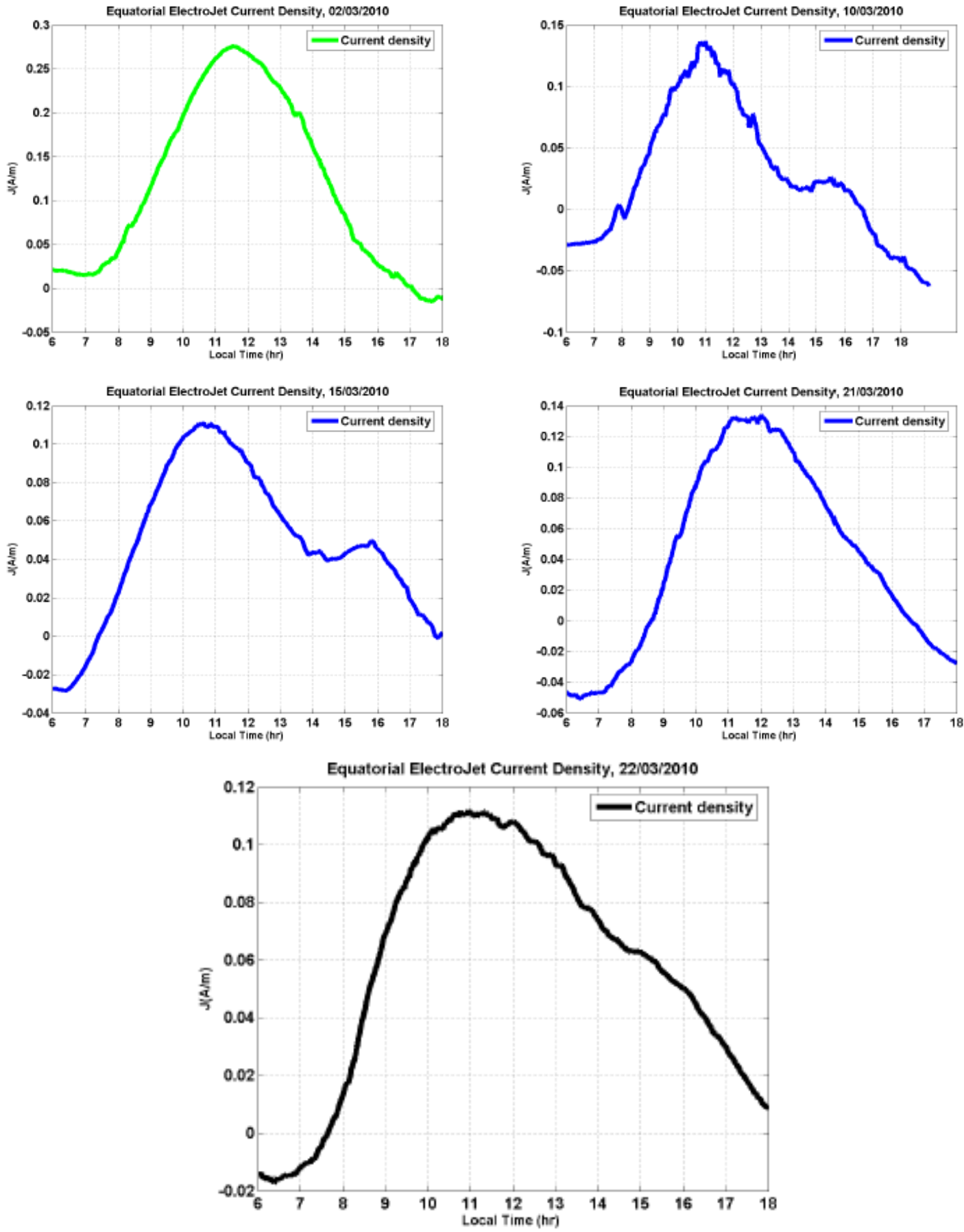

Figure 5: Local time dependence of EEJ current density for March, 2010.

The maximum peak of the EEJ current density, which is obtained from ground-based magnetometer measurements, in agrees with those obtained from theoretical calculation using different models and with some existing results obtained from satellite data from other regions were similar studies had been carried out(see in details Patrick Alken and Stefan Maus). The average peak of EEJ current density from the figure 3-5 is about $0.15 \mathrm{~A} / \mathrm{m}$. This means that a change of $30-80 \mathrm{nT}$ of $\Delta \mathrm{H}$ at ground is equivalent to an equatorial ionospheric current density of 0.1-0.15 A/m over the Ethiopian ionosphere. In other words, an EEJ current density of 0.1$0.15 \mathrm{~A} / \mathrm{m}$ in the ionospheric E-region would produce a value of $\Delta \mathrm{H} 30-80 \mathrm{nT}$ over the Ethiopian ionosphere.

\section{Conclusion}

Ground observations of $\Delta \mathrm{H}$ associated with the EEJ, can be taken as an indication of the equatorial electrojet current density in the ionospheric E-region. We therefore, believe that the mathematical equation (18) will be useful in prediction of the EEJ current density along the magnetic equator as a function of local time 
over Ethiopian ionosphere. The average peak of EEJ current density from figure 3-5 is about $0.15 \mathrm{~A} / \mathrm{m}$ for the three months.

\section{Reference}

[1]. Alken P, Maus S (2007) Spatio-temporal characterization of the equatorial electrojet from CHAMP, Ørsted, and SAC-C satellite magnetic measurements. J Geophys Res 112:A09305.

[2]. C.A. Onwumechili, P.O. Ezema Latitudinal and vertical parameters of the equatorial electrojet from an autonomous data set, Journal of Atmospheric and Terrestrial Physics Volume 54, Issues 11-12, 1992, Pages 1535-1544

[3]. Chandrasekhar N, Arora K, Nagarajan N (2014) Evidence of short spatial variability of the equatorial electrojet at close longitudinal separation. Earth Planets Space 66:110

[4]. Chapman S (1951) The equatorial electrojet as detected from the abnormal electric current distributions above Huancayo, Peru, and elsewhere. Arch Meteorol Geophys Bioclimatol A4:368-390

[5]. Doumouya V, Cohen Y (2004) Improving and testing the empirical equatorial electrojet model with CHAMP satellite data. Ann Geophys 22:3323-3333

[6]. Doumouya V, Cohen Y, Arora BR, Yumoto K (2003) Local time and longitude dependence of the equatorial electrojet magnetic effects. J Atmos Terr Phys 65:1265-1282

[7]. Doumouya V, Vassal J, Cohen Y, Fambitakoye O, Menvielle M (1998) Equatorial electrojet at African longitudes: first results from magnetic measurements. Annales Geophysicae, European Geosciences Union 16(6):658-666.

[8]. Fambitakoye, Mayaud PN (1976) Equatorial electrojet and regular daily variation SR-1. A determination of the equatorial electrojet parameters. J Atmos Terr Phys 38:1-17

[9]. Forbes JM (1981) The equatorial electrojet. Rev Geophys Space Phys 19:469-504

[10]. Hagan ME, Forbes JM (2002) Migrating and nonmigrating diurnal tides in the middle and upper atmosphere excited by tropospheric latent heat release. J Geophys Res 107(D24):4754.

[11]. Hamid NSA, Liu H, Uozumi T, Yumoto K (2013) Equatorial electrojet dependence on solar activity in the Southeast Asia sector. Antarct Record 57(3):329-337

[12]. Hamid et al. Empirical model of equatorial electrojet based on ground-based magnetometer data during solar minimum in fall, Earth, Planets and Space (2015) 67:205

[13]. Onwumechili CA (1997) The equatorial electrojet. Gordon and Breach Science Publishers, Amsterdam, The Netherlands

[14]. Onwumechili CA, Ezema PO (1992) Latitudinal and vertical parameters of the equatorial electrojet from an autonomous data set. J Atmos Terr Phys 54(11):1535-1544

[15]. Sabaka TJ, Olsen N, Purucker ME (2004) Extending comprehensive models of the Earth's magnetic field with Ørsted and CHAMP data. Geophys J Int 159:521-547

[16]. Shume EB, Denardini CM, Paula ER, Trivedi NB (2010) Variabilities of the equatorial electrojet in Brazil and Peru. J Geophys Res 115

[17]. Stening RJ (1995) What drives the equatorial electrojet? J Atmos Solar-Terr Phys 57:1117-1128

[18]. Yumoto K, the MAGDAS Group (2007) Space weather activities at SERC for IHY: MAGDAS. Bull Astronomic Soc India 35:511-522 